\title{
A NOVEL INDEX FOR ATMOSPHERIC AEROSOL TYPES CATEGORIZATION WITH SPECTRAL OPTICAL DEPTHS FROM SATELLITE RETRIEVAL
}

\author{
Tang-Huang Lin ${ }^{\mathrm{a}, *}$, Gin-Rong Liu ${ }^{\mathrm{a}}$, and Chian-Yi Liu ${ }^{\mathrm{a}}$ \\ ${ }^{\text {a }}$ Center for Space and Remote Sensing Research, National Central University, Taoyuan 32001, Taiwan \\ thlin@csrsr.ncu.edu.tw
}

Commission VIII, WG VIII/3

KEY WORDS: AOD, SSA, Aerosol Type, NGAI, MODIS, AERONET

\begin{abstract}
:
In general, the type of atmospheric aerosols can be efficiently identified with the characteristics of optical properties, such as Ångström exponent (AE) and single scattering albedo (SSA). However, the retrieval of SSA is not frequently available to global area which may cause the difficulty in the identification of aerosol type. Since aerosol optical depth (AOD) can be easily requested, a novel index in terms of AOD, Normalized Gradient Aerosol Index (NGAI), is proposed to get over the constraint on SSA providing. With the NGAI derived from MODIS AOD products, the type of atmospheric aerosols can be clearly categorized between mineral dusts, biomass burning and anthropogenic pollutants. The results of aerosol type categorization show the well agreement with the ground-based observations (AERONET) in AE and SSA properties, implying that the proposed index equips highly practical for the application of aerosols type categorization by means of remote sensing. In addition, the fraction of AOD compositions can be potentially determined according to the value of index after compared with the products of CALIPSO Aerosol Subtype.
\end{abstract}

\section{INTRODUCTION}

The most commonly methods used to determine aerosol types are the characteristics of of aerosol properties in AOD and AE, which are functions of wavelength. By applying threshold criteria to scatter plots, in which AE is plotted against AOD, the aerosol type can be identified. However, this kind of methods could be limited under the circumstances of mixed aerosols. Therefore, this paper proposes to develop a novel retrieval algorithm to identify aerosol type as well as which the fraction of component.

\section{DATA AND METHODOLOGY}

\subsection{AERONET}

AERONET is a global aerosol observation network with more than 400 ground-based stations worldwide. In this study, the spectral AOD and SSA measured from the sites of AERONET at $0.44,0.67,0.87$, and $1.02 \mu \mathrm{m}$ were used to characterize the optical properties for different aerosol types. According to the Angström formula (Eq. (1)), the $\mathrm{AE}$ can be calculated from AOD measurements at $0.44 \mu \mathrm{m}$ and $0.67 \mu \mathrm{m}$ for the analysis of aerosol particle size distibutions. The SSA data were extracted from Almucantar inversion product at $0.44,0.67,0.87,1.02 \mu \mathrm{m}$ to investigate radiative properties for different aerosol types. AERONET observations played a vital role to provide the accurate aerosol properties without surface reflectance information as it's observe from ground toward the sun. Hence, the accuracy of MODIS satellite aerosol retrieval results is usually validated against the AERONET data.
The retrieved aerosol products from the AERONET Level 1.5 and Level 2.0 data from 1998 to 2012 were used in this study. AERONET stations have been chosen which are located in Africa, Middle East and Asia.

\begin{tabular}{|c|c|}
\hline AERONET Station & Aerosol Type \\
\hline Solar Village (24N,46E) & Dust \\
\hline Tamanrasset $(22 \mathrm{~N}, 5 \mathrm{E})$ & Dust \\
\hline Beijing (39N,116E) & Dust \\
\hline Beijing (39N,116E) & AP \\
\hline Hong Kong (22N,114E) & AP \\
\hline Taihu (31N,120E) & AP \\
\hline Chiang Mai (18N,98E) & BB \\
\hline Mukdahan (16N,104E) & BB \\
\hline Pimai (15N,102E) & BB \\
\hline
\end{tabular}

Table 1. The sites of AERONET station with main aerosol type.

Dust particle, Biomass burning (BB) and Anthropogenic pollutants (AP) aerosols are the target types focused in this study. Beijing, Solar Village and Tamanrasset station were categorized as Dust affected areas. Tamanrasset and the Solar Village is located in Africa and Middle East desert regions, therefore these station seriously affected by dust. AP properties was analyzing in urban areas, selected station data located in southeastern coastal cities of China (Beijing, Taihu and Hong Kong Hok Tsui).

AP aerosols were collected during August to September due to influence of Dust aerosol or BB aerosol can be avoided and quantitatively justified AP aerosol optical properties. BB in Indochina and Asia occurs frequently in March and May every 
year. During this period, deliberate burning of forest, crops and rice bran for reclaim agricultural land were produce vigorous $\mathrm{BB}$ aerosols. Pimai, Mukdahan, Chiang Mai station were selected as the source for $\mathrm{BB}$ station in order to obtain $\mathrm{BB}$ aerosol.

\subsection{Satellite Data}

Moderate Resolution Imaging Spectroradiometer (MODIS) is one of key instruments aboard the Terra and Aqua satellites. Both satellite is placed in a sun synchronous orbit at $705 \mathrm{~km}$. Terra passes from north to south across the Asia (local time 10:30), while Aqua passes south to north across the Asia (local time 13:30). MOD04 Corrected Optical Depth Land products used in this study were downloaded from MODIS website. MOD04 data contain AOD from 0.47, 0.55 and $0.67 \mu \mathrm{m}$ at 10 $\mathrm{km}$ resolution. The aerosol types were identifying with calculation the AOD slope at 0.47 and $0.67 \mu \mathrm{m}$. This study was to validate the accuracy of aerosol type identification results. First, points were selected in AERONET station. Next, points from AERONET station were used to retrieve the MODIS aerosol. Finally, identification of the difference between MODIS aerosol and AERONET were analyzed and discussed.

Cloud-Aerosol Lidar and Infrared Pathfinder Satellite Observations (CALIPSO) launches with linearly-polarized pulses of light at $1064 \mathrm{~nm}$ and $532 \mathrm{~nm}$. CALIPSO satellite standard products can be measured atmospheric aerosols and clouds vertical distribution situation, as well as its optical and physical properties. In addition, providing atmospheric cloud and aerosol observations to help us better understand the cloud and aerosol effects on climate caused. CALIPSO satellite is one of the afternoon constellations which close to the passage of time through the same area with MODIS / Aqua satellite. Thus, identification of aerosol type method established in this study and CALIPSO satellites Vertical Feature Mask (VFM) products were to discover the applicability of aerosol identification method.

Clouds and the Earth's Radiant Energy System (CERES) research project contain solar-reflected and Earth-emitted radiation from the top of the atmosphere to the Earth's surface. The vital factors to control the earth's climate were attributable to the interaction between greenhouse gases, aerosols, clouds and solar radiation. CERES observations can be more understanding of the relationship between them and given the dynamic force for improvement in climate research. The identification of aerosol type method established in this study will combined with CERES top of atmosphere and bottom of atmosphere shortwave radiation fluxes products to assess changes of direct radiative forcing under cloudless conditions for different types of aerosols. The develop aerosol types identification model spatial resolution is $0.1^{\circ} \mathrm{X} 0.1^{\circ}$ and CERES product spatial resolution is $1^{\circ} \mathrm{X} 1^{\circ}$. In order to further the analysis, the spatial resolution of the develop model was adjusted to $1^{\circ} \mathrm{X} 1^{\circ}$. Then, select the type of aerosol in the entire region and evaluate the same type aerosol. Therefore, the impact of the single type aerosol can be screened out from the grid point to explore other types of contaminants aerosol for analysis the radiative values will reduce the aerosol types impact.

\subsection{Aerosol Optical Properties Variability}

The AERONET data were downloaded from the MODIS website. The datasets were extracted through different month to evaluate and analyze the types of aerosols distribution over the study area. The results indicate different between types of aerosols and its radiative properties. Comprehensive comparisons for aerosol radiative properties are presented in Table 2. It consists of AE Dust aerosols $(0.66 \pm 0.055), \mathrm{AE} \mathrm{BB}$ aerosols $(1.449 \pm 0.096)$ and AE AP aerosols $(1.058 \pm 0.291)$. Results display that Dust particle size greater than BB and AP, thus AE can use as initial identification between Dust and nondust aerosol. SSA may represent aerosols absorption properties. SSA closer to 1 implies stronger scattering; conversely, SSA closer to 0 implies stronger absorption. SSA absorption strength can be used to highlight the BB aerosol as a highly absorbent. SSA BB aerosol is significantly smaller than Dust and AP aerosol, indicate absorption of BB aerosol is greater than Dust and AP aerosol. Related research results indicates SSA BB $(0.87 \pm 0.06)$ and SSA AP $(0.95 \pm 0.05)$ (Griggs and Noguer 2002) similar with SSA statistical results of this study. Hence, the statistical results showed the accuracy of the selected aerosol type and aerosol parameters.

\section{PROPOSED ALGORITHM}

\subsection{Type Identification of Aerosols}

Accordint to the Ångström empirical formula below (Ångström 1961),

$$
\tau=\beta \times \lambda^{-\alpha}
$$

Where: $\tau(\lambda)$ is AOD; $\beta$ is atmospheric turbidity coefficient; $\lambda$ is the wavelength (m); $\alpha$ for the aerosol particle size distribution. The different wavelength $\left(\lambda_{1}, \lambda_{2}\right)$ of AOD, Angstrom's turbidity formula can be rewritten as Eq. (2) to obtain the AE, and AOD slope equation can be expressed as Eq. (3), combined Eq. (2) and Eq. (3) can be derived in Eq. (4) as following.

$$
\begin{aligned}
& \frac{\tau_{1}}{\tau_{2}}=\left(\frac{\lambda_{2}}{\lambda_{1}}\right)^{\alpha} \\
& \text { Slope }=\frac{\left(\tau_{2}-\tau_{1}\right)}{\left(\lambda_{2}-\lambda_{1}\right)}
\end{aligned}
$$

$$
\text { Slope }=\tau_{2} \times B \times\left(1-A^{\alpha}\right)
$$

Where $A=\frac{\lambda_{2}}{\lambda_{1}}, B=\frac{1}{\left(\lambda_{2}-\lambda_{1}\right)}$

Eq. (4) display different types of aerosol influenced slope changes essentially affected by AOD and AE parameters. However AOD were aerosol extinction coefficient and function of concentration, concentration will affect AOD and cause changes in the slope of AOD. For the conditions under light aerosol loading, it is still difficult to discriminate the type of aerosols as Figure 1 shows. 


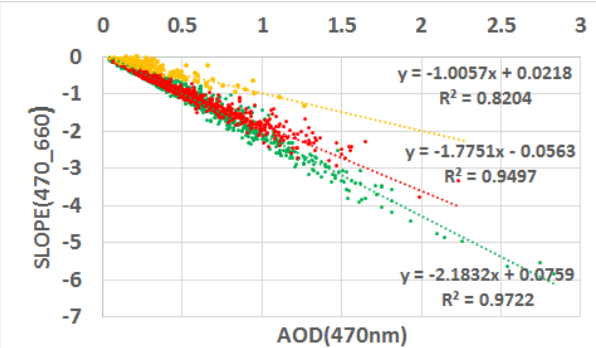

Figure 1. AOD aerosol slope $(0.47 \& 0.66 \mu \mathrm{m})$ for Dust, AP and BB with AOD $(0.47 \mu \mathrm{m})$.

After removing the influence of the concentration of the aerosol, Dust, AP and BB aerosols emerge gradient distribution (Figure 2 ), this could clearly identify Dust, AP and BB aerosol and avoid a misinterpret occurred. Thus a novel index, Normalized Gradient Aerosol Index (NGAI), is defined by Eq. (4) after normalization of aerosols loading for aerosol type identification.

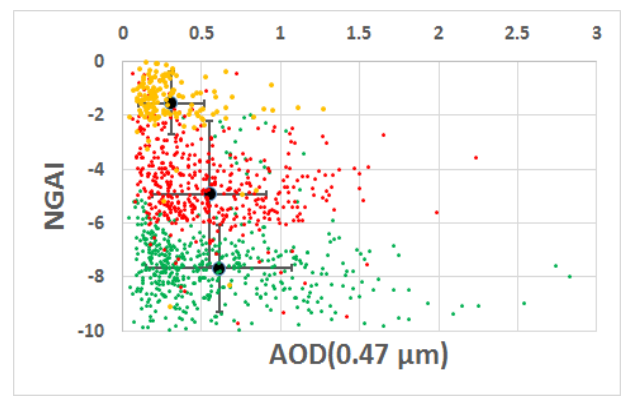

Figure2. Same as Figure 1, but after normalization.

\subsection{AOD Fractionating}

Since the ambient atmosphere not only presence sole aerosol type, threshold set by NGAI interpolation methods can be an objective to further analysis under different mixing weight (AP $+\mathrm{BB}, \mathrm{AP}+$ Dust) conditions . In order to verify accuracy of mixing weight between different aerosol types, determining mixing weight aerosols in NGAI method with corresponding to CALIPSO satellite observations assessment. CALIPSO products provide Extinction coefficient profile and aerosol type distribution can use to calculate the vertical profile of different aerosol types. Figure 3 shows CALIPSO vertical profile only have mixed of BB and AP aerosol, thus NGAI method used to identify a mixed aerosol. CALIPSO is calculated by NGAI method in aerosol mixed case indicated BB and AP contributed AOD showing a good linear relationship respectively. The results displayed in the aerosol mixed case, NGAI can obtain further ratio of different types of aerosols with individual contribution to AOD. The develop NGAI equation not affected by aerosol concentration; hence the threshold value can be set to identification aerosol type identification and do interpolation between different types of aerosol threshold.

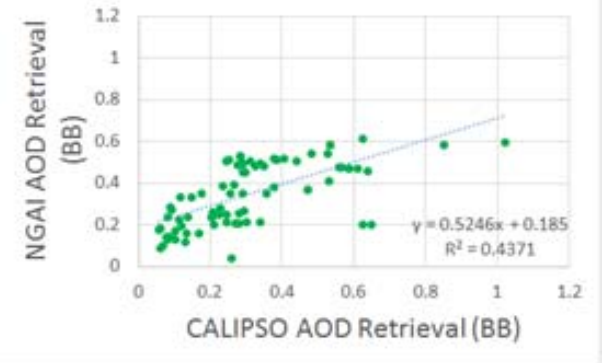

Figure 3. The comparison between CALIPSO and NGAI for fractional $\mathrm{AOD}_{0.53 \mu \mathrm{m}}$ and $\mathrm{AOD}_{0.55 \mu \mathrm{m}}$ of $\mathrm{BB}$ type.

\section{DISCUSSION}

A novel aerosol index (NGAI) for identifying the type of aerosols from MODIS data is presented in this study. After validated with ground-based measurements (AERONET) and satellite products (CALIPSO), the results indicate the highly practical of NGAI in aerosol type categorization by means of remote sensing. Meanwhile, the potential to provide the fractional AOD of component for mixing aerosols from NGAI is also suggested. More case studies should be examined for applicability of the new aerosol index.

\section{ACKNOWLEDGEMENTS}

This work was financially supported by the Taiwan Ministry of Science and Technology Grant MOST 104-2111-M-008-007 and MOST 104-2526-M-008-002.

\section{REFERENCES}

ÅNgstrÖM, A. (1961). Techniques of Determinig the Turbidity of the Atmosphere1. Tellus, 13, 214-223.

Giles, D., Holben, B., Eck, T.F., Sinyuk, A., Smirnov, A., Slutsker, I., Dickerson, R., Thompson, A., \& Schafer, J. (2012). An analysis of AERONET aerosol absorption properties and classifications representative of aerosol source regions. Journal of Geophysical Research: Atmospheres (1984-2012), 117. 